\title{
COMPARATIVE ANALYSIS OF CRACK PROPAGATION IN VIBRATING CANTILEVER BEAMS OF BRASS AND ALUMINIUM
}

\author{
JN Mahto', S C Roy ${ }^{2}$ \\ ${ }^{I}$ Department of Mechanical Engineering, BIT Sindri, Dhanbad (Jharkhand) \\ ${ }^{2}$ Department of Mechanical Engineering, BIT Sindri, Dhanbad (Jharkhand)
}

\begin{abstract}
In present investigation, attempt has been made to find out the propagation of crack growth rate of vibrating cantilever beams of brass and aluminium from free end to fixed end. The values of $V, B, F$, and $D$ were observed and calculated at different frequency of $60 \mathrm{~Hz}, 80 \mathrm{~Hz}, 100 \mathrm{~Hz}$ and $120 \mathrm{~Hz}$. Fixing length of specimens of both the materials were kept constant at a value of $400 \mathrm{~mm}$ and $350 \mathrm{~mm}$ during experimental work. Cracks of size $2 \mathrm{~mm} \times 2 \mathrm{~mm}$ were artificially generated at $155 \mathrm{~mm}$ and $123 \mathrm{~mm}$ from free end. A mathematical model was developed using dimensional analysis to find out the value of crack growth rate along the vibrating cantilever beam. Calculated values of $G$ were plotted to observe crack growth rate along the beam for different specimens of brass and aluminium at different crack location. Plots were compared and analysed to find out the effect of Crack location at different frequency.
\end{abstract}

Keywords: Accelerometer, Cantilever Beam, Crack Growth Rate, Fixing Length, Frequency, Velocity of Vibration

\section{INTRODUCTION}

Engineering structures are designed to withstand the loads they are expected to be subject to while in service. There is a continuous demand of energy, due to technological development, which is being fulfilled by various conventional and non-conventional energy resources. There are many critical components that cannot be just spared, therefore, it is very important to know the effect of crack position on the life of a machine components in its working condition. Crack is one of the most common faults that if develops, may cause catastrophic damages in structures. The input vibration at different frequency affects crack growth rate at different position from free end towards fixed end.

\section{LITERATURE REVIEW}

It has been observed that both crack location and crack depth has noticeable effect on the modal parameters of the cracked beam[1]. The effect of vibration is evident in the work of researchers for the applications of Wavelet Transformation to detect crack-like damage in structures $[2,3]$. Crack propagation simulated with previously obtained experimental data may be more preferable in that under this situation, the fatigue tests are inexpensive, fast and noncomplex in nature. It has proven to be a powerful and versatile soft-computing method which is quite efficient in modelling complicated linear and nonlinear relationships based on of experimental data in a number of engineering fields[4]. It is important to note that even in bone injury crack growth rate plays a vital role. Gibson worked with bone to characterize fatigue life of bone and suggested that crack growth rate in different cortical regions is different $[5]$.

\section{MATHEMATICAL MODEL}

In the present work, the vibration characteristics of uniform cantilever beam were investigated for different specimens of brass and aluminium. The variables considered for the analysis were velocity of vibration(V), force per crosssectional area (W), distance of crack from fixed end (B), frequency of the force per fixing length $(\mathrm{F})$, distance of accelerometer from free end (D). Here, the total number of variables $=6$, number of fundamental units $=3$, number of dimensionless group $=3$, functional relationship, $\Phi(\mathrm{V}, \mathrm{D}$, $\mathrm{F}, \mathrm{B}, \mathrm{G})=0$. Using Buckingham Pi Theorem the value of $\mathrm{G}$ is obtained as $G=\left(10^{-14}\right)\left(D^{3} F^{2}\right)\left(\frac{B}{V}\right)$. The values of $\mathrm{G}$ were calculated for fixing length of $400 \mathrm{~mm}$ and at frequency of $60 \mathrm{~Hz}, 80 \mathrm{~Hz}, 100 \mathrm{~Hz}$ and $120 \mathrm{~Hz}$ for both the materials. Graphs were plotted for the specimens under forced vibration and were observed to compare and characterize the behaviour of the specimens.

\section{EXPERIMENTAL WORK}

Specimens were positioned as a cantilever beam as shown in Fig-1.Two specimens of each material were prepared and a crack was artificially generated on two specimens of each material. Cracks with cross section $2 \mathrm{~mm} \times 2 \mathrm{~mm}$, across the width of specimen were ground using horizontal grinding machine on a $500 \mathrm{~mm}$ long rectangular bar of cross section $50 \mathrm{~mm} \times 12 \mathrm{~mm}$. The location of crack was artificially generated at $155 \mathrm{~mm}$ and $123 \mathrm{~mm}$ from free end in all the specimens of each material. Experiment were conducted to record the observe values of velocity of vibration at different values of $\mathrm{B}, \mathrm{F}$ and $\mathrm{D}$. Observations were made for fixing length of $400 \mathrm{~mm}$ and $350 \mathrm{~mm}$ of the beam at different frequency of $60 \mathrm{~Hz}, 80 \mathrm{~Hz}, 100 \mathrm{~Hz}$ and $120 \mathrm{~Hz}$. 


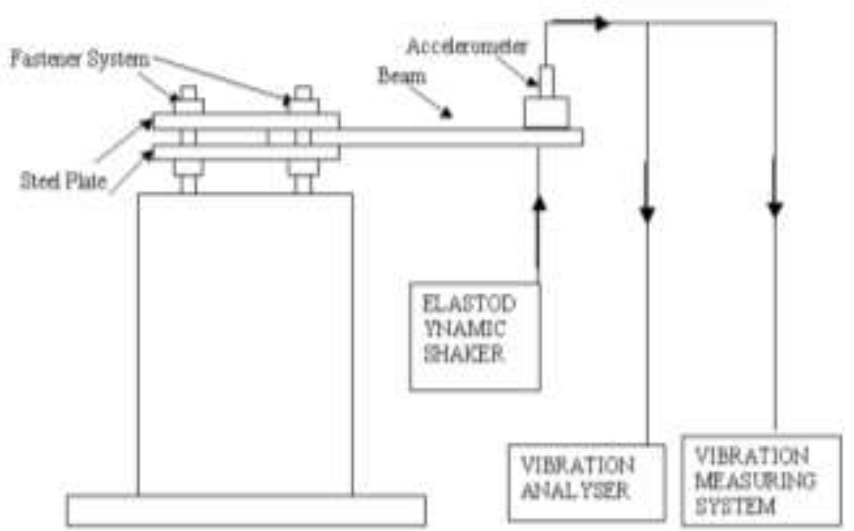

Fig-1: Block diagram of forced vibration Experimental setup

\section{RESULTS AND DISCUSSIONS}

The values of crack growth rate were calculated using function, $G /\left(D^{2} \cdot F\right)=f\left(B / D, V / D^{2} \cdot F\right)$. Calculated values of crack growth rate at fixing length of $400 \mathrm{~mm}$ of vibrating cantilever beam, at different frequency of $60 \mathrm{~Hz}, 80 \mathrm{~Hz}, 100$ $\mathrm{Hz}$ and $120 \mathrm{~Hz}$ were plotted in fig- 2 to fig- 5 to compare the results. Variation of crack growth rate were shown in fig-6 to fig- 9 for fixing length $350 \mathrm{~mm}$ of vibrating cantilever beam at frequencies of $60 \mathrm{~Hz}, 80 \mathrm{~Hz}, 100 \mathrm{~Hz}$ and $120 \mathrm{~Hz}$. Variation of crack growth rate for brass and aluminium were shown in fig-10 to fig-13 at fixing length of $400 \mathrm{~mm}$ and $350 \mathrm{~mm}$ at different frequency as mentioned.

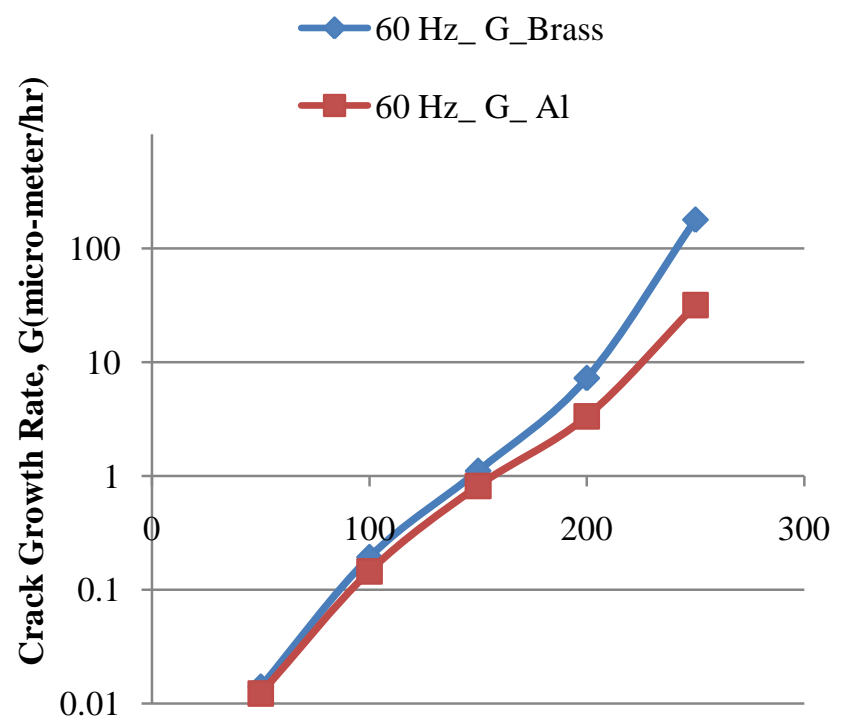

Distance of Accelerometer from Free End, D(in mm)

Fig-2: Variation of crack growth rate of brass and Al at 60 $\mathrm{Hz}$ with fixing length $400 \mathrm{~mm}$

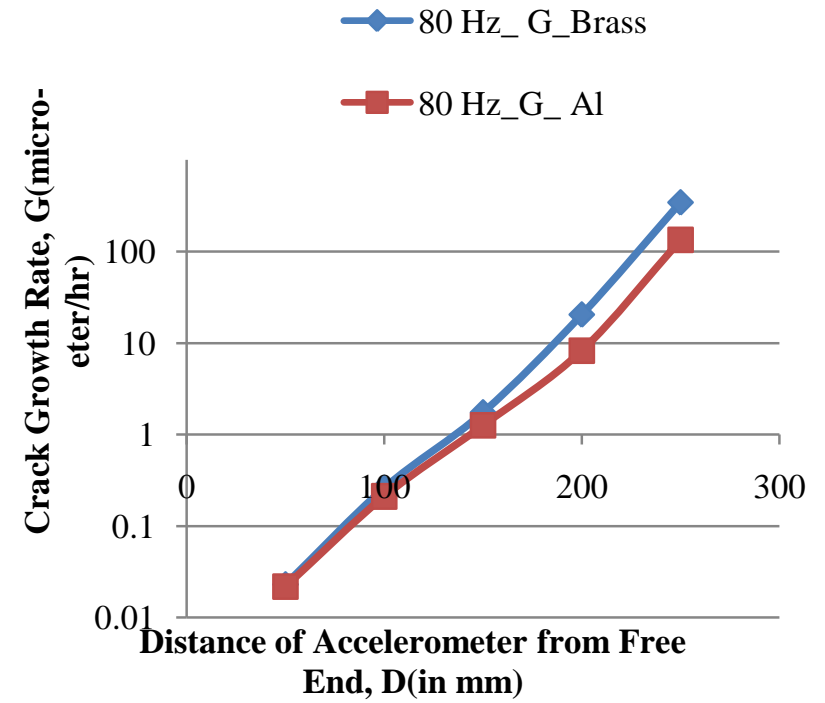

Fig-3: Variation of crack growth rate of brass and $\mathrm{Al}$ at 80 $\mathrm{Hz}$ with fixing length $400 \mathrm{~mm}$

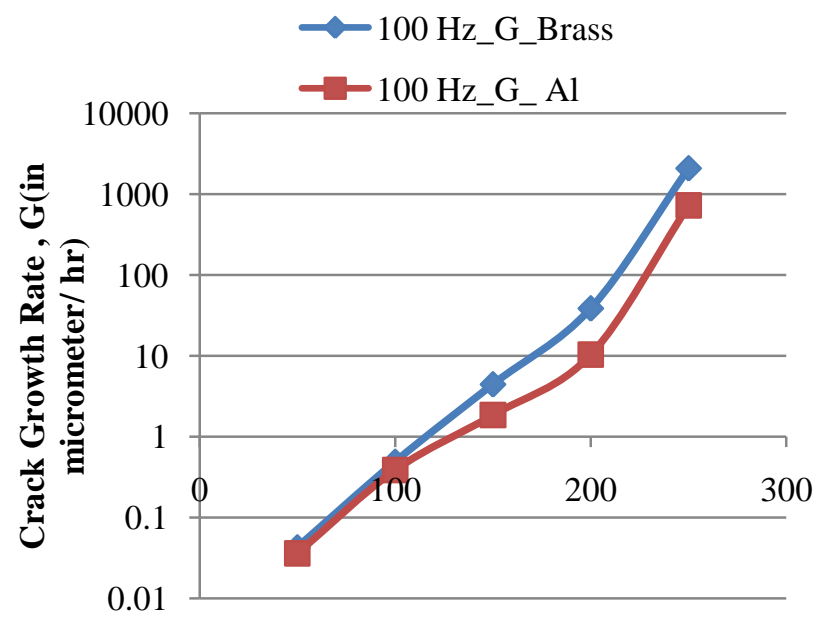

Distance of Accelereometer From Free End, $D$ ( in mm)

Fig-4: Variation of crack growth rate of brass and $\mathrm{Al}$ at 100 $\mathrm{Hz}$ with fixing length $400 \mathrm{~mm}$

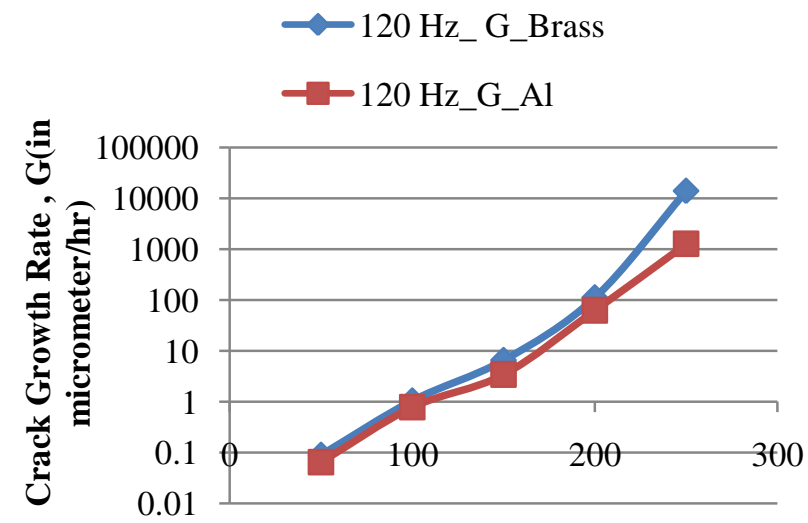

Distance of Accelereometer From Free End, $D$ ( in mm)

Fig-5: Variation of crack growth rate of brass and $\mathrm{Al}$ at 120 $\mathrm{Hz}$ with fixing length $400 \mathrm{~mm}$ 


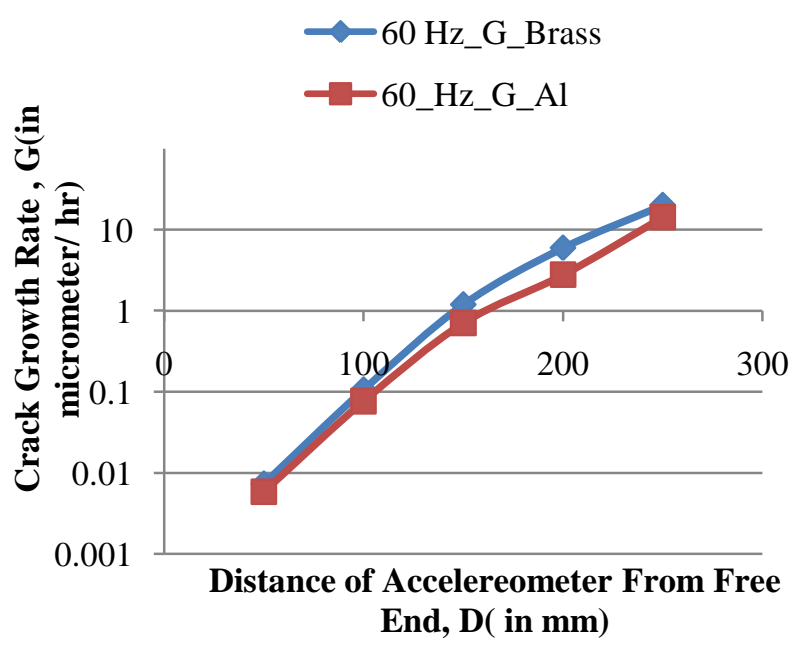

Fig-6: Variation of crack growth rate of brass and Al at 60 $\mathrm{Hz}$ with fixing length $350 \mathrm{~mm}$

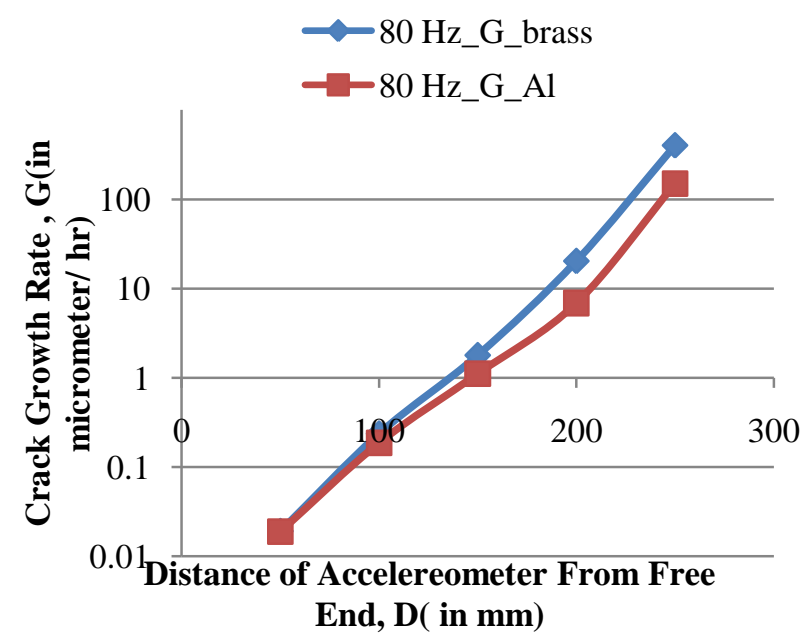

Fig-7: Variation of crack growth rate of brass and $\mathrm{Al}$ at 80 $\mathrm{Hz}$ with fixing length $350 \mathrm{~mm}$

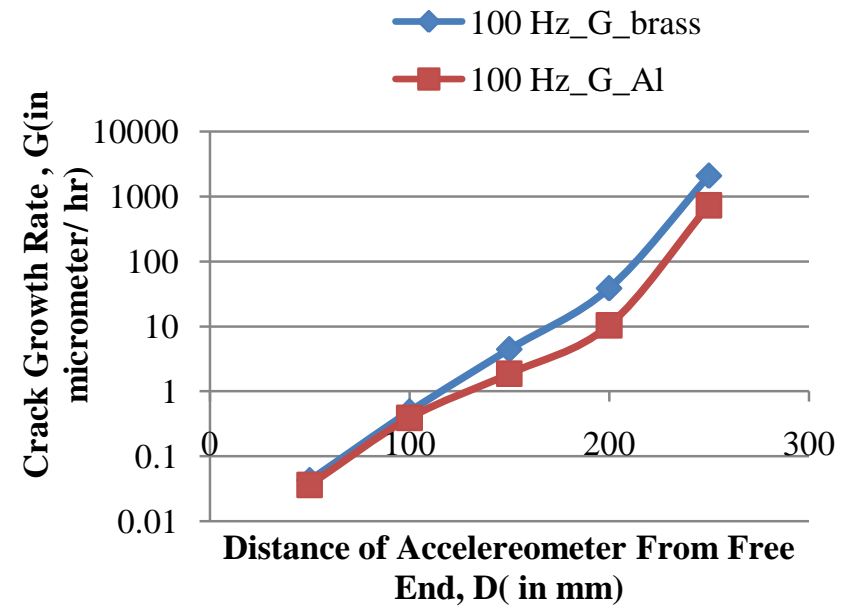

Fig-8: Variation of crack growth rate of brass and Al at 100 $\mathrm{Hz}$ with fixing length $350 \mathrm{~mm}$

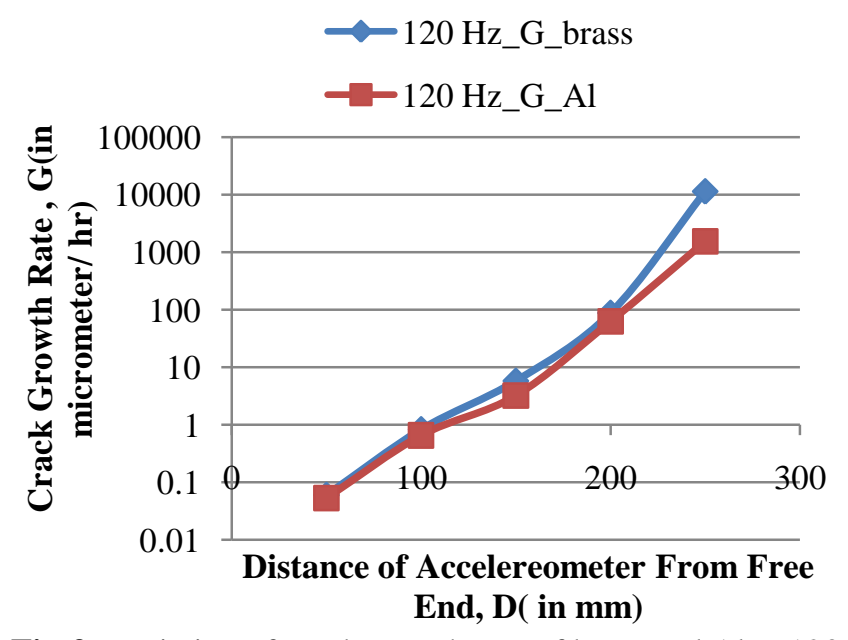

Fig-9: Variation of crack growth rate of brass and $\mathrm{Al}$ at 120 $\mathrm{Hz}$ with fixing length $350 \mathrm{~mm}$

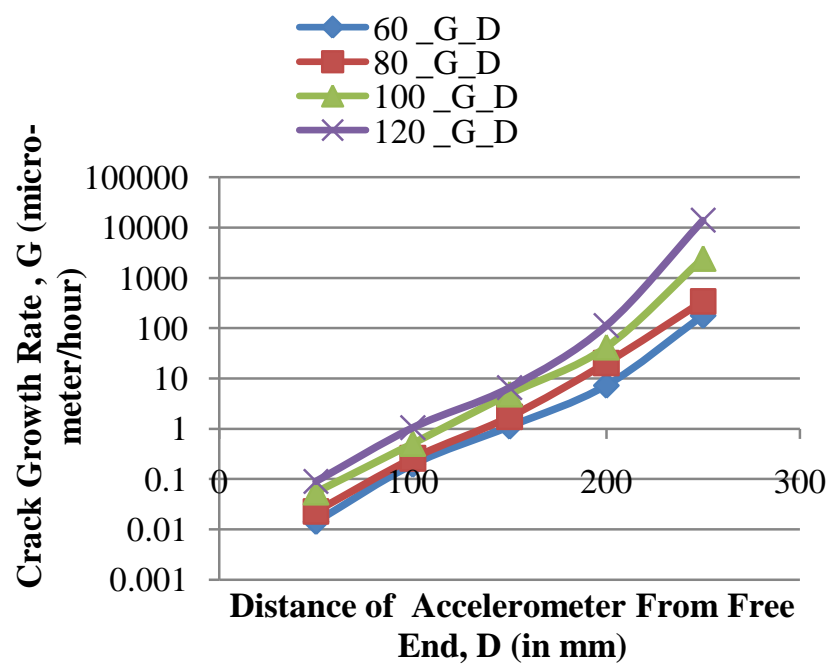

Fig- 10: Determination of crack growth rate for accelerometer moving from free end for brass with fixing length $400 \mathrm{~mm}$.

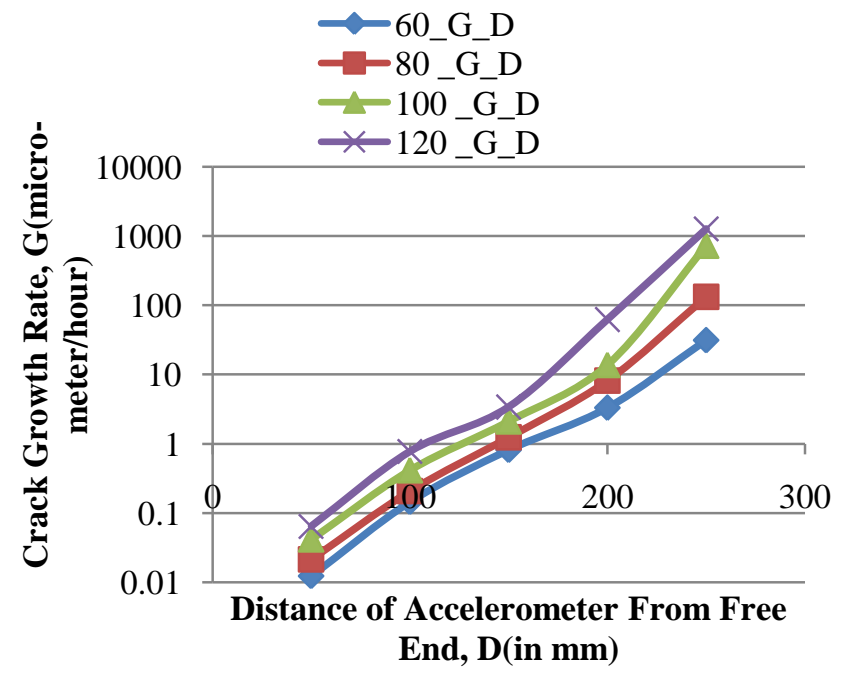

Fig-11:Determination of crack growth rate for accelerometer moving from free end for aluminium with fixing length 400 $\mathrm{mm}$. 


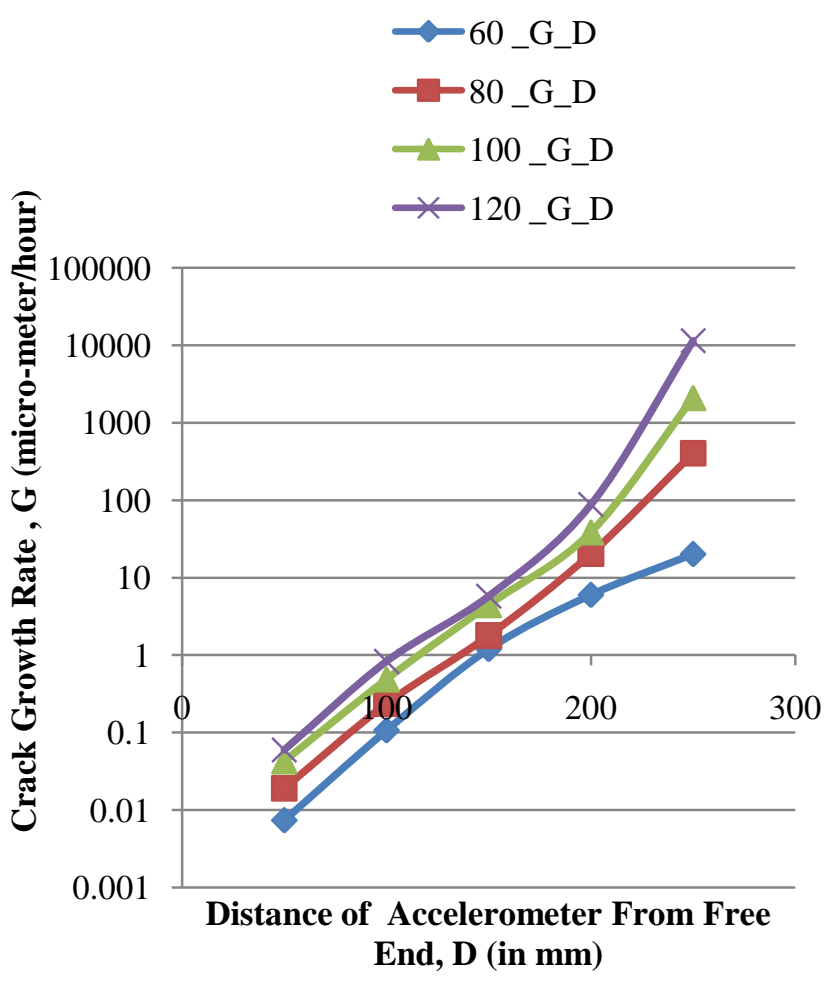

Fig- 12: Determination of crack growth rate for accelerometer moving from free end for brass with fixing length $350 \mathrm{~mm}$

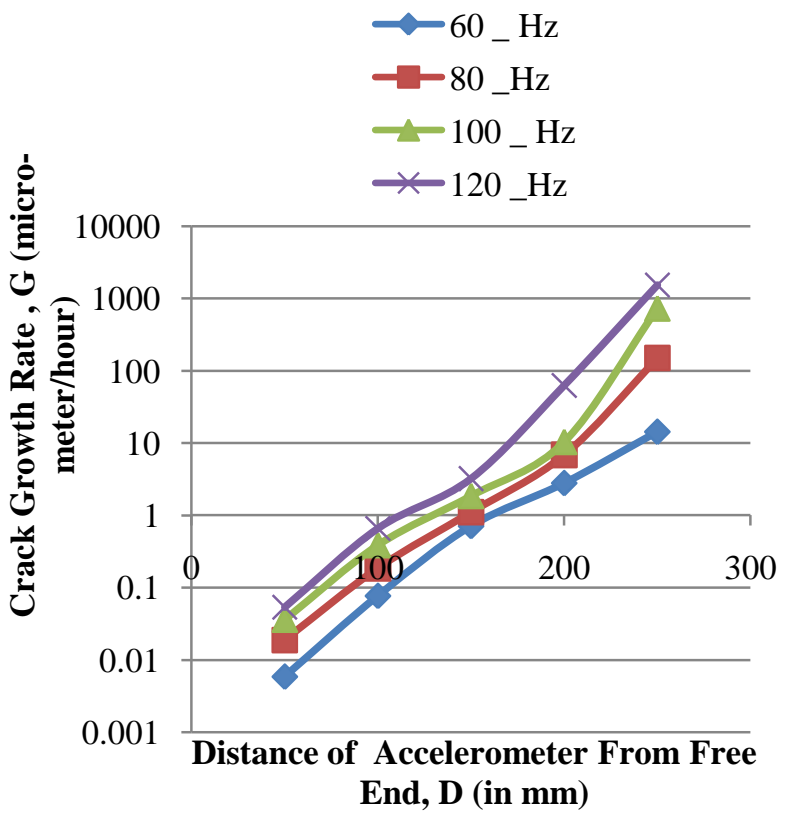

Fig- 13 : Determination of crack growth rate for accelerometer moving from free end for aluminium with fixing length $350 \mathrm{~mm}$

\section{CONCLUSION}

From fig- 2 to fig- 9, it was found that crack growth rate of brass is more than aluminium. This difference in crack growth rate was due to density difference, as the density of brass has $8500 \mathrm{~kg} / \mathrm{m}^{3}$ and that of aluminium has $2700 \mathrm{~kg} / \mathrm{m}^{3}$. Fig- 10 to fig- 13 show that crack growth rate increases with increase in frequency of vibration.

\section{NOMENCLATURE}

$\begin{array}{ll}\text { V } & \text { Velocity of vibration }(\mathrm{m} / \mathrm{s}) \\ \text { W } & \text { force per cross-sectional area }\left(\mathrm{N} / \mathrm{m}^{2}\right) \\ \text { B } & \text { Distance of crack from free end }(\mathrm{m}) \\ \text { F } & \text { Frequency of the force per fixing length }(\mathrm{m}) \\ \text { D } & \text { Distance of the accelerometer from free end }(\mathrm{m}) \\ \mathrm{G} & \text { Crack growth rate }(\text { micrometer } / \mathrm{hr})\end{array}$

\section{REFERENCES}

[1]. Batabyal AK, Sankar P, Paul TK, Crack Detection in Cantilever Beam using Vibration Response, Vibration Problems ICOVP-2007, Springer Netherlands, ISBN: 978-14020-9091-2 (print), Oct. 09, 2008, pp 27-33.

[2]. Ovanesova AV and Suarez LE, "Applications of Wavelet Transforms to Damage Detection in Frame Structure," Engineering Structure, vol. 26, pp. 39-49, 2004. [3]. Hansang K and Hani M, "Damage Detection of Structures by Wavelet Analysis," Engineering Structure, ol. 26, pp. 347-362, 2004.

[4]. Al-Nashash H, Al-Assaf HY, and Mansoor BW, "Laser speckle for materials classification utilizing wavelets and neural networks image processing techniques," Journal Materials Evaluation, vol. 59, pp. 1072-1078, 2001.

[5]. G. Pantazopoulos, A review of defects and failures in brass rods and related components, Practical Failure Analysis, 3 (4) (2003), pp. 14-22.

\section{BIOGRAPHIES}

Mr Jitendra Nath Mahto is Assistant Professor, Department of Mechanical Engineering, BIT Sindri, Jharkhnad, India. He has done his B.E. in Mechainacal Engineering from BIT Mesra, Ranchi and M.Tech. from BIT Sindri, Dhanbad, Jharkhand. At present doing Ph. D. from BIT Sindri, Dhanbad and thesis has been submitted in Binoba Bhave University, Hazaribag. He has five years industrial experience and 10 years teaching experience. His field of specialization is Design. Mr. J. N. Mahto has published several papers in various national, international conferences and journals. He has guided students for their M. Tech. work.

Dr. S.C.Roy is working as a Professor \& Head in Mechanical Engineering Department, BIT, Sindri, Jharkhand, India. He has done his Ph.D. from Jadavpur University. He has engaged in teaching and research activities since the last 35 years. He has published several papers on various research areas, in national and international journals. 